\title{
Imaginário de Alunos de Licenciatura em Física Sobre Algumas Questões Relativas ao Ensino dessa Disciplina
}

\author{
Future High School Teachers' Imaginary About Physics Teaching \\ Leandro L. da Silva', Thirza P. Sorpreso ${ }^{2}$, Maria José P. M. de Almeida ${ }^{3}$
}

${ }^{1}$ Aluno de Doutorado em Educação, gepCE/FE/UNICAMP, ${ }^{2}$ Aluna de Doutorado em Educação, gepCE/FE/UNICAMP, 3 gepCE/FE/UNICAMP Apoio: CNPq. llondero@unicamp.br thirza.ps@gmail.com y mipma@unicamp.br,

\section{Resumo}

Neste estudo buscamos compreender o imaginánio de licenciandos em física sobre o papel dos pesquisadores em ensino de física, a função da escola e o objetivo do ensino da física. Para tanto, analisamos respostas a um questionánio aplicado numa disciplina de um curso de formação de professores na Universidade Estadual de Campinas em São Paulo, Brasil. Como apoio teórico nos sustentamos na vertente da análise de discurso iniciada por $M$. Pêcheux. Os resultados apontam para a constituição de imaginários comuns à maioria dos estudantes, mas também mostram algumas divergências.

Palavras-chave

Ensino de Física, Imaginário, Formação Inicial.

\section{Abstract}

In this artide we try to understand the future high school teachers' imaginary about physics teaching researchers' work, school function and goals of physics teaching. We analyze undergraduate students discourses enunciated in a teacher formation course at State University of Campinas, in São Paulo, Brazil. As theoretical reference we make use of the discourse analysis as developed by $M$. Pêcheux. The results point analogous imaginaries, but point some divergences too.

\section{Key-words}

Physics Teaching, Imaginary, Initial Teacher Formation

\section{Introdução, Justificativa e Apoio Teórico}

Estudos como os de Sorpreso e Almeida (2008), Araújo e Vianna (2007), Jesus et al. (2007), Abib e Tedeshi (2004), Almeida (2004), Terrazzan et al. (2003) evidenciam a preocupação dos pesquisadores do Ensino de Física com a formação inicial de professores.

Não é fácil considerar toda a diversidade de aspectos que devem ser considerados quando se pensa essa formação, uma vez que o futuro professor precisa estar preparado no que tange aos diferentes olhares para os processos de ensino e de aprendizagem, aos conteúdos que irá ensinar e às suas condições de produção e às políticas públicas em que estará inserido profissionalmente, entre outros tantos aspectos a serem considerados. Quando alguns desses aspectos são abordados, freqüentemente são negligenciados os modos do futuro professor (licenciando) pensar o ensino e o que a ele está relacionado. 0 mais comum é que sejam considerados apenas seus 
conhecimentos em relação aos conteúdos propriamente ditos, quer sejam os da educação ou os da física e disaiplinas afins, em se tratando do futuro professor de física. E então os conhecimentos prévios dos estudantes são objetos das preocupações dos professores na universidade Nesse sentido, pesquisadores do ensino da física produziram inúmeros trabalhos sobre concepcões alternativas e mudança conceitual.

Na tentativa de tormar mais abrangente o espectro de informações sobre o futuro professor, neste estudo procuramos compreender como estudantes cursando uma disciplina de licenciatura em Física se posicionam em relação ao papel do pesquisador em ensino de física, à função da escola e aos objetivos do ensino da física. Para essa compreensão, investigamos aspectos do imaginário desses estudantes buscando indícios em suas respostas a um questionário respondido num dos primeiros dias de aula.

Ressaltamos a importância das imagens que os futuros professores, manifestam, imagens estas que consideramos fatores condicionante das mediações de ensino possíveis em sala de aula. Admitimos que tanto os futuros professores devem tomar consciência do funcionamento de seu imaginário, como os formadores de professores devem trabalhá-lo em seus cursos.

Utilizamos como apoio teórico a análise do discurso na vertente iniciada por Michel Pêcheux e as noções que possibilitaram a estruturação do estudo, tais como a noção de imaginário. Recorremos principalmente a textos desenvolvidos no Brasil por Eni P. Orlandi. Essa vertente considera que a linguagem não é transparente, compreende o discurso como efeito de sentidos entre locutores, algo que é posto em funcionamento. Já 0 imaginário é pensado como um mecanismo constituído por meio de relações interdiscursivas, produzidas em diferentes momentos e situações sóaio-históricas.

Compreender o discurso como algo posto a funcionar implica em compreender as condições de produção desse discurso. De acordo com Orlandi (2005, p.30), as condições de produção:

\section{[...] compreendem fundamentalmente os sujeitos e a situação. Também a memória faz} parte da produção do discurso. A maneira como a memória 'aciona', faz valer, as condicốes de producãa é fundamental [...]. Podemos considerar as condiçáes de produção em sentido estrito e temos as circunstâncias da enunciação: é o contexto imediato. $E$, se as considerarmos em sentido amplo, as condigấes de produção induem o contexto sóaio-histórico, ideológico.

Sendo assim, o mecanismo imaginário produz imagens do sujeito e do objeto do discurso, dentro de um contexto sócio-histórico. Por meio do mecanismo imaginário o locutor se posiciona, posiciona seu interlocutor e o objeto do discurso. Esse imaginário "assenta-se no modo como as relações sociais se inscrevem na história e são regidas, em uma sociedade como a nossa, por relações de poder" (Orlandi, 2005, p.42). Essa perspectiva faz parte do funcionamento da linguagem, condicionando os sujeitos na produção de discursos, induindo aqueles que se inserem nas mediações em sala de aula. Compreendendo aspectos do imaginário e suas relações com as condições de produção em que se constituem e são evidenciados, compreendemos o modo como o discurso está sendo produzido.

Nos discursos dos licenciandos podem estar presentes elementos diversos, como aqueles que se referem ao papel da escola, ao ensino de física, e dos quais eles tiveram contato em diferentes momentos como, por exemplo, na Educação Básica ou no Ensino Superior. A presença de tais elementos evidencia sua influência em seus imaginários.

Posto isso, procuramos contribuir com as reflexões sobre o ensino de Física, já que, dentro da perspectiva da Análise de Discurso, esse imaginário pode influenciar os posicionamentos dos futuros professores frente à realidade, vivida e interpretada, e na qual eles vão atuar. Dessa 
forma, num país que apresenta uma carência de profissionais com boa formação conceitual e didático-pedagógica, parece ser relevante a compreensão dos imaginários manifestados para que possamos identificar, já na formação inicial, aspectos a serem trabalhados com os estudantes, aspectos esses que levam em consideração os papéis a serem desempenhados pelos pesquisadores e pela escola.

\section{Propósito, Questões de Estudo e Desenvolvimento}

Tendo em vista as considerações anteriores, buscamos neste estudo compreender como os futuros professores se posicionam em relação ao papel do pesquisador em ensino de física, à função da escola e aos objetivos do ensino da física.

Procuramos encontrar resposta para a seguinte questão: Como se constitui o imaginário reconhecido no discurso de estudantes de licenciatura em física sobre o papel atribuído aos pesquisadores em Ensino de Física, à função da escola e aos objetivos do ensino da física?

Uma questão que pode ser desdobrada em outras. Como o imaginário dos futuros professores se manifesta quando eles são questionados sobre:

\section{Que papéis atribuem aos pesquisadores em ensino de física? \\ Que funções atribuem à escola básica? \\ $>$ Que objetivos e importância conferem ao ensino da física?}

Essas questões indicam a necessidade de investigação e reflexão que revelem elementos mais palpáveis e norteadores. Assim, seguimos os procedimentos descritos a seguir.

Para o desenvolvimento do estudo, tomamos como espaço as ações realizadas na disciplina "Conhecimento em Física Escolar II" ( $2^{\circ}$ semestre de 2008) cursada por 18 estudantes. Essa disciplina é parte integrante do currículo da Licenciatura em Física da Universidade Estadual de Campinas em São Paulo, Brasil, e é indicada no $2^{\circ}$ semestre do curso.

No semestre em que as informações aqui analisadas foram coletadas a disciplina "Conhecimento em Física Escolar II" tinha como objetivo contribuir para que o licenciando: a) reflita acerca de alguns aspectos políticos e culturais da ação educativa; b) conheça e reflita sobre aspectos da cotidianidade do Ensino Médio, com foco no ensino da física; c) se posicione em relação às possibilidades e limites do ensino escolar da física em nível médio; d) compreenda alguns aspectos próprios da pesquisa educacional sobre educação em ciências; e) se aproprie de alguns conhecimentos e habilidades básicos na elaboração do planejamento de aulas de física para o Ensino Médio.

A programação curricular da disciplina ao longo do semestre procurou contemplar os seguintes tópicos: a) inter-relações entre Ciência, Tecnologia, Sociedade e Ambiente; b) relevância da História da Ciência no Ensino da Física; c) importância da leitura no ambiente escolar de textos literários, de divulgação científica e/ou originais de cientistas.

No primeiro dia de aula da disciplina, a docente responsável, uma das autoras deste trabalho, após se apresentar e solicitar que cada aluno também se apresentasse, aplicou um questionário com o objetivo de obter algumas informações sobre os estudantes e sobre como interpretavam até aquele momento alguns aspectos da prática didático-pedagógica. $O$ questionário continha questões abertas que possibilitavam a livre resposta pelos estudantes.

Neste estudo o foco de análise concentra-se nas respostas que eles forneceram para as seguintes questões: 1) Diga o que você pensa que fazem os pesquisadores em ensino de física, e comente o que você consideraria um papel importante desses profissionais em nossa 
sociedade? 2) Em sua opinião quais são as funções da escola em nossa sociedade? 3) Quais devem ser os principais objetivos para se ensinar física no EM?

Após a utilização do questionário, organizamos as informações coletadas mediante tabulação, e aqui evidenciamos resultados e comentamos alguns casos que nos pareceram mais significativas em função de nossos propósitos, redigindo os trechos mais expressivos dentro de cada uma das "classes" estabelecidas a posteriori, com vistas a aproximar do leitor elementos que elucidam nossas análises. Preservaremos os nomes dos autores das respostas usando nomes fictícios.

\section{Alguns Resultados: papéis, funções e objetivos atribuídos pelos licenciandos}

Divididas as respostas, aqui consideradas como discursos dos licenciandos em classes, seguem a seguir as classes de papeis atribuídos ao professor que notamos em alguns de seus discursos:

\section{Papéis atribuídos ao pesquisador em ensino de Física}

\section{> Identificação de problemas com o objetivo de resolução}

Nesta primeira classe encontram-se as falas nas quais é possível notarmos posições dos estudantes afirmando que a pesquisa em ensino de física preocupa-se com os efeitos e resultados do ensino; como, por exemplo, nos trechos reproduzidos a seguir.

"Pesquisam efeitos e resultados do sistema atual de ensino de física, procuram maneiras para torná-lo mais eficiente"(Rodrigo)

"Trabalham para tentar identificar os problemas encontrados nas salas de aula, na aprendizagem da física, seja fazendo acompanhamentos de sala, avaliações ou pesquisa de campo" (Ariane).

Com base nessas falas notamos que no imaginário dos estudantes são privilegiados os resultados em detrimento aos processos para se chegar a eles. Também se pode notar o foco exclusivo na sala de aula, ou seja, na educação formal. Provavelmente uma visão apoiada na memória do próprio curso de graduação e/ou do ensino básico, já que, como podemos notar em visitas à escola ou em observações das aulas na universidade, nesses níveis de escolarização é atribuída grande importância aos resultados. A produção final é por vezes ressaltada sem a reflexão com relação ao processo particular que resulta em determinados produtos finais. Talvez a importância conferida à produção pelo licenciando cujo discurso foi aqui reproduzido (Rodrigo) o tenha levado a afirmar que o pesquisador em ensino busca a eficiência.

\section{$>$ Auxílio ao trabalho do professor}

Notamos em muitas falas indícios de que, no ímaginário dos licenciandos, a pesquisa em ensino de física viria em auxílio ao tabalho do professor; esse auxílio seria por meio do estudo de diversas metodologias que poderiam ser utilizadas no ensino e não apenas uma única como no exemplo a baixo.

"Metodologias para o melhor desempenho no ensino, concepções de física e formação de professores. Traz reflexões para as práticas docentes." (Felipe)

"Estudam tudo sobre ensino de física e formação de professores. São um elo entre a situação atual e o que precisa ser feito para melhora-lo" (Marcelo) 
Na fala de Felipe notamos, particularmente, que ele confere importância à pluralidade de metodologias, além da concepção de que a pesquisa em ensino de física pode subsidiar o trabalho do professor no sentido de promover reflexões de sua prática, um imaginário sobre o papel da pesquisa não comum entre os licenciandos.

\section{Funções conferidas à escola}

\section{> Transmissão de conhecimentos sistematizados}

A quantidade mais expressiva de alunos atribuiu à escola a função de transmissão de conhecimentos. Essa visão está em consonância com o papel atribuído anteriormente pelos mesmos alunos ao pesquisador em ensino. Eles não conferiram importância aos processos que ocorrem em sala de aula como pode ser observado mediante a leitura das falas reproduzidas abaixo. Em geral, os estudantes não consideram que "forma" e "conteúdo" em sala de aula compõem juntos o que é ensinado e aprendido, de maneira que em seus imaginários basta um conteúdo ser transmitido ou informado.

"Transmitir conhecimento adquirido pelo homem e acontecimentos que marcaram a humanidade e preparar o aluno para pensar e ser crítico e autônomo" (Rodrigo).

No depoimento de Rodrigo nota-se que além de privilegiar a transmissão esse estudante parece dar ênfase aos acontecimentos que seriam 'marcas' na história da humanidade. É possível que ele estivesse apenas pensando a história composta de marcos importantes e não aquela vista como um processo dinâmico. Entretanto, em seu depoimento, afirma que a escola deve preparar o aluno para pensar, ser crítico e autônomo. Ao fazer tal afirmação o licenciando não parece considerar que a transmissão de informações seja suficiente para 0 desenvolvimento do pensamento, da crítica e da autonomia ou, talvez, ele esteja apenas supondo que essa seja a resposta que dele se espera, talvez ouvida em outra disciplina.

\section{$>$ Preparação para o trabalho}

Encontramos algumas falas típicas que atribuem à escola o papel de preparação para o trabalho, como no exemplo a seguir:

"Estágio para preparar e formar as crianças e os jovens para o trabalho. Maneira de reduzir a dedicação dos pais" (Felipe)

No imaginánio desse licenciando a escola aparentemente serve como preparação para o trabalho e para suprir a educação que segundo ele deveria ser oferecida pela família.

\section{Objetivos atribuídos ao Ensino da física}

\section{$>$ Transmissão de conhecimentos sistematizados}

A função transmissiva da escola também ganha destaque nos objetivos atribuídos ao ensino da física, como se nota na fala a seguir.

"Transmitir aos alunos o conhecimento científico, mostrar leis" (Rodrigo)

Ao afirmar que o objetivo é mostrar leis, Rodrigo ressalta a importância que confere aos resultados científicos. Por outro lado, ao se referir as estratégias de ensino que deveriam ser utilizadas, Rodrigo se contradiz em sua fala comparativamente à anterior:

"Conter contexto histórico, desenvolvimento de leis e exercícios teóricos" 
Esse aluno citou estratégias que valorizam o processo de construção da ciência e seu desenvolvimento e não apenas a simples transmissão de seus resultados. Talvez uma contradição gerada pelo contato anterior desse licenciando com enunciados que se referiam aos recursos que deveriam/poderiam ser usados no ensino da física e que seu imaginário disponibiliza no momento em que ele ocupa seu lugar de licenciando em física.

> Compreensão do mundo/perspectiva cultural/formação da cidadania

Identificamos falas, de alguns licenciandos, que destacam como objetivo do ensino da física aspectos para além de um simples ensino transmissivo. O exemplo reproduzido a seguir é uma dessas falas:

"Oferecer o conhecimento da natureza, fornecer bases para entender a miséria humana, a evolução do pensamento, as revoluções sociais e discussões filosóficas sobre a natureza e o conhecimento" (Felipe)

Para Felipe, segundo seu discurso, o objetivo do ensino da física seria o da compreensão do mundo e da realidade em que vivemos, de pensamento crítico e reflexivo, de formação para a cidadania. Para esse licenciando, o ensino da física poderia proporcionar essa formação. Supomos que, nas concepgões de Felipe o ensino e a própria física não estão separados da realidade social, a física faria parte da sociedade e o seu ensino deveria promover essa compreensão.

\section{Considerações Finais}

Nos imaginários inferidos das respostas do conjunto dos licenciandos que responderam as questões do questionário verificamos, em geral, ao menos dois papéis atribuídos aos pesquisadores em ensino de física, à escola e ao ensino da física e os papéis conferidos por alguns estudantes são, em muitos casos, contraditórios.

Por outro lado, enquanto uma quantidade expressiva de alunos considera a transmissão de conhecimentos sistematizados como papel principal dos pesquisadores em ensino de física, uma parte singela associa o objetivo à compreensão do mundo/perspectiva cultural/formação da cidadania.

No entanto, se nos propomos a buscar elementos de como se constitui o imaginário dos licenciandos, não é o número de uma certa resposta que nos interessa e sim buscarmos identificar a origem das memórias que possibilitaram a constituição dos diferentes imaginários manifestos pela dasse. E nesse sentido, a discussão com os estudantes dos seus próprios discursos é um passo importante de reflexão.

\section{Bibliografia}

Abib, M L V. dos S.; Tedeshi, W. (2004). Expectativas e Concepgões de Professores e Futuros Professores de Física. In: Anais do IX Encontro Nacional de Didática e Prática de Ensina, Curitiba.

Almeida, M. J. P. M. (2004). Discursos da Ciência e da Escola: Ideologia e Leituras Possíveis. Campinas: Mercado de Letras.

Araújo, R. S. e Vianna, D. M. (2007). Perfil dos licenciandos em física da UFRJ, segundo o uso de computadores. In: Atas do XVII Simpósio Nacional de Ensino de Física. São Luis, MA.

Jesus, J. C. O.; Silva, M. da C. e Bumham, T. F. (2007). Formação inicial docente versus área de atuação: um perfil de professores de física no interior da Bahia. In: Atas do XVII Símpósio Nacional de Ensino de Física. São Luis, MA. 
Orlandi, E. P. (2005) Análise do discurso, princípios e procedimentos. Campinas, SP: Pontes.

Sorpreso, T. P.; Almeida, M. J. P. M. (2008). Aspectos do imaginário de licenciandos em física numa situação envolvendo a resolução de problemas e a questão nudear. Cademo Brasileiro de Ensino de Física. 25(1), 77-98.

Terrazzan, E. A.; Silva, L L. da; Clement, L; Santini, N. D. Concepcões de Professores em Formação Inicial sobre aspectos da prática didático-pedagógica. In: Anais da VI Escola de Verão para Professores de Prática de Ensino de Biologia, Física, Química e Áreas Afins - Prática de Ensino: memórias em tempos de mudancas, Niterói. 